\title{
Successfully navigating the early years of a faculty position
}

\author{
Michelle L. Kovarik ${ }^{1} \cdot$ Christopher R. Harrison $^{2} \cdot$ Thomas J. Wenzel ${ }^{3}$ \\ Published online: 21 December 2017 \\ (C) Springer-Verlag GmbH Germany, part of Springer Nature 2017
}

\section{Introduction}

The early years of a faculty position can be an invigorating but challenging experience, given the typical expectations for teaching and completion of scholarly work. Teaching and research are time-intensive activities. Service responsibilities to the institution, department, and perhaps the profession add to a faculty member's responsibilities. Finally, everyone needs time for a personal life. Success in the early years of a faculty position often involves finding the right approach to allocating time and balancing the demands on one's time. The writers of this article bring the perspective of an individual who will soon be standing for tenure at an undergraduate institution, an individual who recently got tenure at a doctoral-granting department, and an individual who has spent a 36-year career at an undergraduate institution and is nearing retirement. The three of us are employed at institutions in the United States, although we suspect that much of the advice included herein is also applicable to new faculty members outside the US. Table 1 provides a number of questions, the answers to which will help a new faculty member navigate the early years of their position. Assuming the faculty member has secured a tenure-track position, one virtue of these early years is that your overall professional goal is obvious - get tenure.

Michelle L. Kovarik

michelle.kovarik@trincoll.edu

Christopher R. Harrison

charrison@mail.sdsu.edu

Thomas J. Wenzel

twenzel@bates.edu

1 Department of Chemistry, Trinity College, Hartford, CT 06106, USA

2 Department of Chemistry and Biochemistry, San Diego State University, San Diego, CA 92812, USA

3 Department of Chemistry and Biochemistry, Bates College, Lewiston, ME 04240, USA

\section{First steps to getting tenure}

\section{Understand the expectations}

The first step to getting tenure, and ultimately in balancing the demands in the early years, is in having a clear understanding of what is expected within your situation to achieve tenure or some other form of a permanent appointment. There are some primarily undergraduate institutions (PUIs) in the US that place a strong emphasis on teaching and have minimal to no expectations for scholarship. PhD-granting institutions will place a strong emphasis on scholarly accomplishments. At most institutions, a new faculty hire will not be given a check list of what must be accomplished to secure tenure. The lack of a check list has negative and positive aspects. If a check list exists, a positive aspect is that by checking all the boxes, a favorable tenure decision is assured. However, if the check list is long and arduous to fulfill, the stress of questioning whether one will be able to check all the boxes in the allotted period of time may become overwhelming. While the absence of a check list may make it seem that the criteria for getting tenure are nebulous, a virtue is that there is no one mandated set of criteria and that different people may secure tenure through different types and mixtures of accomplishments. In cases where expectations are less well-defined, it is helpful to have one-on-one conversations with your colleagues to learn more about their individual interpretations of expectations.

\section{Understand who makes the decision}

It is important to determine where the decision-making entity resides and satisfy the expectations of that entity. Are tenure decisions really made by senior members of a department while institutional entities "above" the department (e.g., tenure and promotion committee, chief academic officer, president, trustees) "rubber-stamp" those decisions? Or is there a history at the institution where department recommendations regarding tenure decisions are overturned by others in the 
Table 1 Questions to ask when considering and for succeeding in a faculty position

General Tenure Expectations

- What is the balance between expectations for teaching, scholarly work and service?

- Who has the primary say in the outcome of tenure decisions (e.g., senior department members, tenure and promotion committee, chief academic officer, president, trustees)?

- What is the timeline for reappointment, promotion, and tenure decisions at your institution?

-What documentation will you need to provide at each review?

Teaching

- What institutional opportunities exist to promote your teaching development?

- Are teaching assistants available to help with your teaching and grading? If so, what regular course or lab-related tasks could you assign to your teaching assistant(s) rather than completing yourself?

- Is the department supportive of active learning approaches in the classroom and laboratory?

-What are the institutional and departmental norms or requirements for syllabus contents, office hours, final grade distributions, and academic accommodations?

- Does the department recognize the need to minimize the number of new teaching preparations during the pre-tenure period?

-What information is used in evaluating teaching (e.g., student evaluations, colleague evaluations)?

- Can a faculty member perform their own evaluation of information specific to their course and include it in their dossier?

- Are there established procedures for classroom visits and feedback by senior colleagues?

Research

- What internal and external funding sources are available to support your research?

-Would it be helpful (and possible) to hire a technician or a postdoc to work full-time in your laboratory?

- Is your department supportive of teaching schedules that leave blocks of time to conduct research?

- Are collaborative projects valued in the tenure process?

- What opportunities are available for you to attend conferences to disseminate your work and identify potential collaborators?

Service

- What priorities do you have for your service activities at your own institution and in your broader professional community?

- What strategies will you employ to protect yourself from excessive service obligations?

process? If one of these entities carries more weight than the other, it is essential to know their expectations.

For example, many undergraduate institutions in the US have raised their expectations that faculty members publish scholarly work. At such institutions, untenured members of the department often have scholarly expectations that exceed what was expected of their senior colleagues, especially those colleagues who were hired many years earlier. Chemistry lends itself to collaborating with students in research, an excellent educational experience for undergraduates. There are instances where senior colleagues at PUIs are not supportive of the growing emphasis that is being placed on publications, perhaps going so far as to express the view that time spent undertaking research detracts from one's teaching. If junior faculty members are expected to undertake research, these individuals may be more interested in the experience that student collaborators get from participating. While tenure committees and chief academic officers usually value the educational experience that students get from conducting research, they rarely are willing to substitute it for the publications expected for tenure. In this situation, the potential exists to get messages from a department that the student educational experiences you are providing are sufficient, whereas the institutional entity actually making the decision does not have that view.

\section{Pursue funding for your research}

The time period to a tenure decision passes quickly and it is important to get a research laboratory up and running as soon as possible. Preliminary data generated in the early years provide the basis for more compelling grant proposals to funding agencies. Most faculty members are given some amount of start-up funds. While it might be tempting to want to stretch these funds out, that may slow down your ability to set up a laboratory and generate important preliminary results.

A faculty member at a $\mathrm{PhD}$-granting institution is fully aware of the need to pursue funding for their work, and likely needs no prodding to vigorously identify potential sources of funds and submit grant proposals. At PUIs, the need to pursue sources of funding for scholarly work may be less emphasized. Many PUIs have institutional programs that provide summer stipends for research students or modest funds to undertake research. Untenured faculty members are often prioritized in these programs, given that they are trying to establish themselves during a probationary period. Even if the norm is that these funds are "rotated" among different members of the faculty, untenured faculty members can often make the case for more frequent rounds of support.

US Federal agencies such as the National Science Foundation (NSF) and National Institutes of Health (NIH) have the Research at Undergraduate Institutions (RUI) and Academic Research Enhancement Awards (AREA - R15) programs, respectively, which are intended for faculty members at less research-intensive institutions. Admittedly, these external grant programs are highly competitive. Many initial submissions are not funded, but feedback from the reviewers and program officers is helpful in determining whether the work has the potential to get funded and how to improve a resubmission in the next cycle. The sooner a faculty member starts this process the better. Direct communication with the program officer, prior to submitting a grant, can be very 
beneficial in determining how a faculty member's research can meet the program officer's goals for the program. Learning what the priorities are for the grant program, and what the program officer may be looking for, increases the likelihood of finding a receptive audience for a research proposal.

A faculty member should also explore all potential avenues for funding. Many regional, state, and non-governmental agencies provide funding; though likely much less than NSF or NIH, this funding is helpful, both in monetary terms and in validating the quality of the research ideas by demonstrating that they are fundable.

Writing proposals is an effective way to develop and refine research ideas, and unsuccessful attempts at securing external support can be used as a justification for continued internal awards with the argument that the funds are needed to generate preliminary data that will make future grant proposals more competitive. Federal agencies and organizations such as the Council on Undergraduate Research [1] offer grant writing workshops or webinars that can provide valuable advice on writing more competitive proposals. Untenured faculty members should approach their institution for support to attend one or more of these sessions and argue that it should not diminish any annual allotment of funds to attend a professional conference. Also, find one or more colleagues who have experience with proposal writing who will provide you with honest critiques of drafts of your proposals.

As much as the feedback in the form of reviews for your proposals is beneficial, participating in the review process can be even more enlightening. A faculty member can volunteer to act as a reviewer for the major funding agencies. Participating in a review, particularly in a panel review, provides a better perspective of what the best and worst grant proposals look like, how reviewers are influenced by what is written, and how the program officer is involved in the selection of submissions. All these insights will influence and improve your subsequent proposals; and as an added bonus, serving as a reviewer for a grant counts as service to the broader scientific community.

\section{Be judicious in taking on service responsibilities}

Another important consideration is to determine the extent to which service to the profession, institution, and department is counted in the tenure decision and be judicious in agreeing to service responsibilities. There never seem to be enough hours in the day for teaching and research obligations; service responsibilities usually detract from the time for these obligations. While people might be favorably impressed by the professional service responsibilities you are undertaking outside the department and the visibility you are gaining in the profession, they often will not substitute such service for the need for scholarly publications. An advantage of being untenured is that it is often easier to turn down service requests by reminding the person asking that you are still in the early stages of establishing yourself as a teacher and scholar.

Since everyone is required to do some service, it is better to pursue those opportunities that may help you develop as a teacher or scholar if they are available. For example, agreeing to organize your department's seminar program often will allow you to invite individuals to campus whose work overlaps with your own, which is an excellent way to get feedback on your early research plans, network with your research community, identify potential collaborators on future projects, or identify outside evaluators for your proposals, manuscripts, or upcoming tenure decision. Similarly, service on an institutional committee focused on promoting and awarding institutional funds for scholarly work will often help develop ideas about how to write more persuasive proposals. Service on an institutional committee aimed at improving teaching will allow you to learn about a variety of teaching styles that may influence your own classroom or laboratory activities. It may be appropriate to volunteer for service opportunities that have the ability to enhance your research or teaching and then use that service as a justification for turning down requests for activities that are peripheral to your main goal of getting tenure. A strong tenure portfolio will present a narrative about who you are as a faculty member and what you bring to your institution. Being selective about your service can help you to build this narrative in a cohesive way.

\section{Other considerations in the early years of a faculty position}

\section{Developing as a teacher}

Many new faculty members soon realize that they have not spent much time thinking about how to be an effective teacher. Many institutions have a learning center that offers programs aimed at promoting effective teaching and learning. These may cover topics that seem relatively mundane (e.g., constructing a syllabus) to those that are more profound (e.g., inclusive teaching). They may function on a one-time, dropin basis or require an individual to commit in advance to a series of sessions, at times with reading or other assignments for each session. There are people who do research on how to be a more effective teacher and how to more effectively promote student learning. Many faculty members are too busy with their own research to have time to follow this literature. Institutionally organized activities are a convenient way to learn about some of the findings of this work and use them to improve one's teaching. Participation in activities such as these may also be used to justify turning down requests for certain service responsibilities that will not help you advance your teaching or scholarly work. 
In the early years, you should advocate for minimizing the number of new courses you teach if your department is not already attentive to this matter. It takes several iterations to feel comfortable with the material in a course, so having some continuity in your yearly teaching assignments is desirable. Whether using a lecture or active learning approach, most teachers will make significant adjustments to their teaching methods in the first few iterations of a new course.

It is also essential to understand how your teaching will be weighted and evaluated in the tenure process. The relative weighting of teaching and research will likely impact the time you devote to these two activities. It is common to hear faculty members at $\mathrm{PhD}$-granting institutions indicate that evaluations of teaching effectiveness are less important than scholarly accomplishments in tenure and promotion decisions. What role do student evaluations have in the evaluation of your teaching? If student evaluations are important, are there particular questions in the evaluation rubric that are deemed more important than others by those making the tenure decision? Can you perform your own student evaluation that is more specific to activities in your course or lab and include the results of that in your dossier? You should consider asking students to complete an informal midterm evaluation of the course so that you can respond to any major issues before the final, formal evaluations are completed at the end of the semester. Do departmental and institutional evaluators have access to the average grades you award and how are such averages considered in the process? What role do colleague letters play? Will colleagues sit in on your classes, and are there established procedures for how these classroom visits and feedback from them are to be conducted? Identify whether there are institutional and departmental norms or requirements for syllabus content, office hours, final grade distributions, and academic accommodations, and conform to those norms.

The growing body of research on how people learn and how to create classroom and laboratory environments that facilitate student learning consistently shows that passive forms of learning (e.g., lecturing and cookbook laboratory experiences) are less effective at promoting student learning than active forms of learning (e.g., students work collaboratively on questions in class and are given open-ended problems to investigate in the laboratory) [2-11]. However, the role of the instructor and nature of the exercise is important in influencing the success of active learning. Some of the programs offered by your institutional learning centers are likely aimed at helping faculty members with the effective use of active learning. However, some students and senior colleagues may be unfamiliar with and therefore resistant to active learning environments. A new faculty member should understand the degree to which active learning already occurs and is encouraged within the department. New faculty members are less likely to encounter pushback from students in an environment where considerable active learning already occurs. There are also more faculty mentors available to help with the effective use of active learning. While the three of us are involved in an NSF-funded project aimed at promoting the use of active learning among analytical chemistry instructors [12], some new faculty members may find in their environment it is wise to take a "safer" approach and primarily use traditional teaching methods until securing a favorable tenure decision.

Whatever teaching methods you choose to use, it is important to maintain reasonable limits on the time you spend preparing for class. Teaching a new course or laboratory is incredibly time-consuming; however, it is possible to spend more time on course preparation than is prudent. Junior faculty may prepare far more lecture material than can possibly be covered in a single class period, spend hours on additional reading in fear of being unable to answer a student question, or get caught up looking for the perfect example problem or video. By starting class preparation with a focus on what you want students to learn, you can focus your class planning and streamline your preparations. This method is sometimes called "backwards course design" because you begin with what you want students to know after a class and work backwards from there to choose lecture topics and class activities [13].

\section{Research collaborations}

It is increasingly common that research questions are undertaken by teams of investigators. Research collaborations are a way to take on more complex problems that require more areas of expertise for success, identify new avenues of work, and bring in new sources of funding. One of the best ways to identify potential research collaborations is by regularly attending a specialty conference in your area of research. These conferences are often smaller and less formal and provide more opportunities for networking with colleagues. It is important when interviewing for a faculty position to ask about the support available to attend conferences to disseminate your work and pursue professional connections. User facilities at nearby institutions and national laboratory facilities are another way to connect with potential collaborators and gain access to specialized equipment that may not be available at your home institution.

Before pursuing collaborations, a new faculty member should gauge his or her department's view of collaborative research. Many departments expect to see some degree of research independence. Often it is expected that persons distance themselves in some way from their prior doctoral and postdoctoral research such that they are not doing the next studies that would have been done with those projects, but using their prior experience in developing new lines of inquiry. Collaborative research projects often have a lead investigator, and a department may expect that a new faculty member 
have at least one project in which he or she is filling that role. However, some PUIs have very limited environments for completing research and may be pleased with any published outcomes that have the name of their school affiliated with it. They may not care whether the faculty member is contributing in a secondary manner to the project so long as he or she is staying engaged in research. With any collaboration, it is important to be able to explain your specific intellectual contribution to the project and how it is essential to the completion of the project.

\section{Lab management}

A new faculty member will soon learn that there is much more to getting a lab started, and maintained, beyond the purchase of chemicals and equipment. One of the most time-consuming aspects of leading a research lab is training the personnel. At the earliest stage, you will be the sole repository of knowledge on how to carry out your desired research. In time, with a large enough group and sufficient overlap in students, the lab will develop its own "institutional knowledge" and may be selfsustaining. If you can afford to hire a lab manager and/or postdoc, that person can become an important source of institutional knowledge, but for many this will not be an option. Spending time early on to develop a set training plan for new students can be extremely valuable. The plan should be clearly written, and the outcomes known in advance so that the student's strengths and weaknesses can be assessed and addressed. Of course, this plan must be tailored to individual students: consider the level of the student and what knowledge he or she brings to the lab.

A common mistake among new faculty is to assume that all students who join your lab will be just as motivated and committed as you were when you first joined a lab. Remember, you are a tenure track professor, so you are the exception not the norm. Clearly communicating your expectations of your research students and setting reasonable goals for them is crucial in maintaining a productive lab. In addition to regular group meetings, it may be beneficial to schedule weekly one-on-one meetings with each research student to monitor and guide his or her individual progress. These regular meetings are also an opportunity to monitor the lab culture and address student concerns before they affect lab morale. Students should understand expectations for using shared reagents and equipment, ordering supplies, repairing or replacing broken items, and other aspects of lab citizenship. Regular and open discussions about authorship and lab citizenship help establish a positive lab culture.

Standard operating procedures (SOPs) are becoming a more frequent safety requirement in many institutions. The SOPs can form the core of the lab's institutional knowledge, particularly when student turnover is high. A thorough collection of SOPs can maintain crucial information in the lab when students leave, and involving students in writing/updating the SOPs will be greatly beneficial should they pursue industrial careers. SOPs ensure that experiments are done consistently, even when executed by different students, and they help maintain compliance in waste disposal and safety practices. Similarly, clear expectations and regular review of lab notebooks will ensure that key information is available when trouble-shooting experiments or drafting manuscripts. Electronic lab notebooks, which are gaining popularity in industry, may benefit you by maintaining permanent, legible records of the work that students perform in your lab.

\section{Creating time for research}

Having time for research is more of an issue for faculty members at PUIs, although as discussed above, all faculty members must resist the urge to participate in numerous service responsibilities to the institution and profession that detract from one's ability to write proposals, undertake research, and write manuscripts. Understand what help is available through teaching assistants and staff (e.g., grading, instructional laboratory preparation, instrument maintenance) and delegate responsibilities to these individuals. Faculty members with a relatively heavy teaching load should advocate for a course and lab schedule that leaves blocks of time for research activities. One possibility is to request one or two days of the week with no classes. Another is to have unbalanced semesters with a heavier teaching load in one. Be judicious in the number of assignments and laboratory reports in your courses so as to not overwhelm yourself with grading responsibilities. In planning your research program, develop a mix of short-term and longterm projects and balance high-risk, high-impact projects with more straightforward work.

For faculty at PUIs, the summer is a vital time for getting research completed. This is the best time to work with and train undergraduate student collaborators. Make clear that you expect them to continue the work in some capacity during the academic year. If your department does not have a system in place that encourages academic year research for credit, advocate for such a possibility with your students. Undergraduate students who have been able to conduct research in the summer make much more progress during the academic year than those who have not had a summer experience. One reason is that you have more time to train them in the summer. Another is that they know the time constraints of different aspects of the project and make better use of their time. During the semester, you may be able to design special projects for students in laboratory courses that help advance your research. Coursebased undergraduate research experiences (CUREs) are known to improve student learning outcomes and keep PUI faculty research projects moving forward during the academic year $[14,15]$. 


\section{Final comments}

With the overall goal of securing tenure, there is one more crucial step that can be easily overlooked - document everything in a timely manner. It is easy to believe, when you are busy with teaching, research, and service activities, that you will remember all the pertinent items to include in your tenure application. Invariably, something may be forgotten or overlooked. As soon as possible determine the timeline for reappointment, tenure, and promotion decisions, and the format and limitations of reappointment and tenure application packages (e.g., page limits, document types) and begin to compile materials for these applications. It is important to provide evaluators with a thorough application that encompasses your record and accomplishments without overwhelming them with every document you have produced or piece of correspondence you have received. Make digital copies of letters of thanks, acceptance letters, and even rejection letters as soon as you get them. Store them in a specific tenure folder on your computer along with all other relevant materials (e.g., grant proposals, manuscripts, an up-to-date CV). Ask a committee chair for a formal letter of thanks for service, whether it is an on-campus or professional activity. Such letters will often highlight specific contributions you have made that your tenure evaluators may not be aware of or will omit in their letters. Collecting everything together over the years into a wellorganized folder will help you alleviate the stress that may occur when preparing your tenure application and allow you to carefully evaluate which materials to include in the package. When the application is compiled, be sure to emphasize the importance of what you have done. Do not expect that value of your work (e.g., publications, grants, service) will be properly recognized on its own, particularly as higher levels of review will be conducted by faculty and administrators with little to no knowledge of your field and its challenges.

Given the need to balance teaching, research, service, and a personal life, it might be tempting to conclude that those individuals who are good multitaskers are more likely to succeed as a faculty member. In reality, studies have shown that multitasking is an ineffective way to complete work. Most people are more productive when they focus on one activity at a time [16]. It is important to compartmentalize one's time into teaching, research, service, and personal activities. Adopt and adhere to a weekly schedule where certain blocks of time are devoted to one activity. Use breaks in the academic calendar for work on one or two larger projects (e.g., writing a grant proposal or manuscript) that need attention, and delay handling less time intensive responsibilities to the shorter time intervals available when classes resume. It is important to prioritize responsibilities and focus on those activities that are most urgent. It is also important to recognize that your priorities will change over an academic year and over the years leading up to a tenure decision. Establish a timetable for completing the various activities associated with a larger project and ensure that you adhere to that timetable, even if it means putting some other things on the back burner.

New faculty members may at times feel overwhelmed by all the responsibilities in the first few years. Those who are successful understand the expectations, prioritize their responsibilities, and focus on those most important for securing tenure. Fulfilling the many responsibilities of a faculty position does become easier with repetition and experience, leading most to conclude that a career as a faculty member is a busy but rewarding endeavor.

\section{References}

1. Council on Undergraduate Research (https://www.cur.org/). Accessed on December 1, 2017.

2. Project 2061. Washington, DC: American Association for the Advance of Science; 1985.

3. Science teaching reconsidered: a handbook. Washington, DC: National Academies Press; 1997.

4. Bransford J, Brown AL, Cocking RR. How people learn: brain, mind, experience and school. Washington, DC: National Academies Press; 2000.

5. Pienta NJ, Cooper MM, Greenbowe TJ. Chemists' guide to effective teaching. Prentice Hall: Upper Saddle River; 2005.

6. Hohlach JM, Grove N, Bretz SL. Pre-service teacher as researcher: the value of inquiry in learning science. J Chem Educ. 2007;84: 1530-4.

7. Discipline-based education research: understanding and improving learning in undergraduate science and engineering. Washington, DC: National Academies Press; 2012.

8. Kober N. Reaching students: what research says about effective instruction in undergraduate science and engineering. Washington, DC: National Academies Press; 2015.

9. Cooper MM. Evidence-based reform of teaching and learning. Anal Bioanal Chem. 2014;406:1-4.

10. Galloway KR, Bretz SL. Measuring meaningful learning in the undergraduate chemistry laboratory: a national cross-sectional study. J Chem Educ. 2015;92:2006-18.

11. Sandi-Urena S, Cooper MM, Stevens R. Effect of cooperative problem-based lab instruction on metacognition and problemsolving skills. J Chem Educ. 2012;89:700-6.

12. Analytical Sciences Digital Library (http://home.asdlib.org/). Accessed on 1 Dec 2017.

13. Wiggins GP, McTighe J. Understanding by design. 2nd ed. Alexandria: Association for Supervision and Curriculum Development; 2005.

14. Auchincloss LC, Laursen SL, Branchaw JL, Eagan K, Graham M, Hanauer DL, et al. Assessment of course-based undergraduate research experiences: a meeting report. CBE Life Sci Educ. 2014;13: 129-40.

15. Weaver GC, Russell CB, Wink DJ. Inquiry-based and researchbased laboratory pedagogies in undergraduate science. Nat Chem Biol. 2008;4:577-80.

16. Rosen C. The myth of multitasking. New Atlantis Spring. 2008: 105-10. 


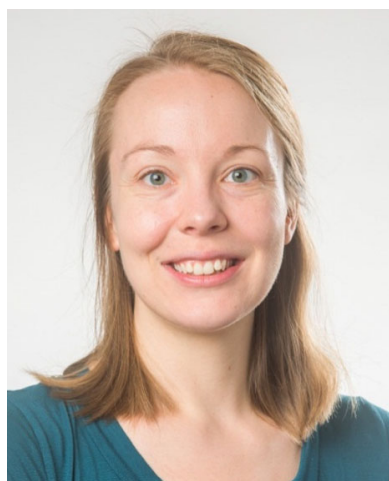

Michelle L. Kovarik is Assistant Professor of Chemistry at Trinity College in Hartford, Connecticut. Her research interests include microfluidics, single-cell measurements, and the use of fluorescently labeled peptides for enzyme assays. She is also involved in scholarly activity to develop materials for the undergraduate analytical chemistry curriculum that emphasize active learning and engage students with the primary literature.

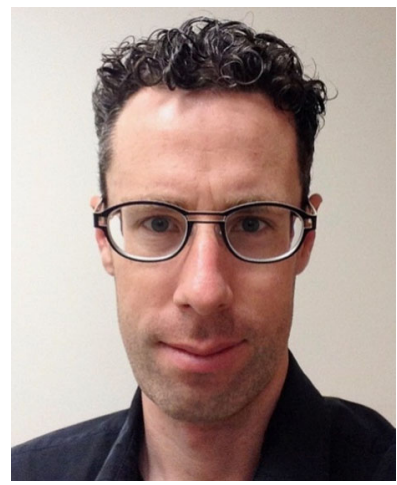

Christopher R. Harrison is Associate Professor of Chemistry at San Diego State University. His research focus centers around the separation of biomolecules via capillary electrophoresis, with a particular emphasis on developing new methods for athlete anti-doping tests, and exploring the fundamentals of electroosmotic flow control. He has also been active in incorporating digitals tools and methods in his teaching, and developing active learning materials for analytical chemistry education.

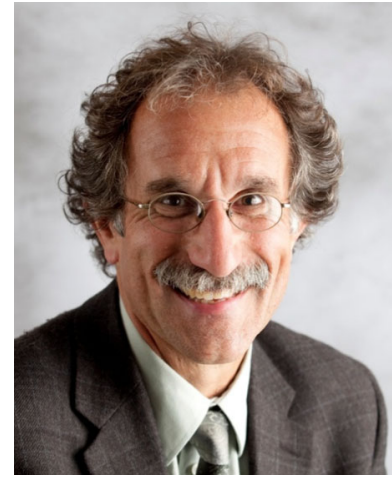

Thomas J. Wenzel is the Charles A. Dana Professor of Chemistry at Bates College in Lewiston, Maine. He currently carries out research with the aid of undergraduate students in the area of chiral NMR shift reagents. His research accomplishments were recognized with the 2010 American Chemical Society Award for Research at an Undergraduate Institution. He is active in efforts to reform the undergraduate analytical chemistry curriculum to include inquiry- and projectbased experiences. 